\title{
The Effect of Steel Fiber and Internally Curing on the Strength of Self-Consolidated Concrete
}

\author{
Sami Ayyad ${ }^{1}$, Eleyan Issa Jamal Issa ${ }^{1} \&$ Sallam Shoroq ${ }^{1}$ \\ ${ }^{1}$ Department of Civil Engineering, Amman Arab University, Amman, Jordan. \\ Correspondence: Eleyan Issa Jamal Issa, Department of Civil Engineering, Amman Arab University, Amman, \\ Jordan.
}

Received: January 5, 2020

Accepted: January 30, 2020

Online Published: January 31, 2020

doi:10.5539/mas.v14n2p86

URL: https://doi.org/10.5539/mas.v14n2p86

\begin{abstract}
The main idea of this study is to find the effect of steel fiber on the strength and internally curing of self-consolidated concrete (SCC), by using lightweight aggregate (LWA) from available porcelain. The work includes two stages; the first stage involved making several experimental mixes and then choosing the one that corresponds to international standards with natural properties. The second stage was adding lightweight aggregate (LWA) by replacing $15 \%$ of sand with saturated fine lightweight aggregate (LWA) as internal curing material to study the change in the Mechanical properties of SCC. Four concrete mixes were used with different volume fractions of hooked steel fibers were incorporated $0 \%, 0.5 \%, 1 \%$, and $1.5 \%$. Results showed that adding steel fibers provides a slight increase in compressive strength while significant enhancement in tensile properties was observed. Furthermore, replacement of fine aggregate by (LWA) causes an increase in hydration which leads to higher compressive and tensile strengths. Results of the rate of absorption indicate that adding steel fibers has beneficial effects.
\end{abstract}

Keywords: concretes, compressive strength, reinforced concrete, mechanical properties, self-consolidated concrete, flexural, steel fibers

\section{Introduction}

The development of self-consolidated concrete (SCC) is improving the product quality and efficiency of the building. SCC homogeneously distributed and without air voids due to its weight, without any additional compaction. SCC (Okamura, H. 1997). The development of self-consolidated concrete SCC is improving the product quality and efficiency of the building. SCC homogeneously distributed and without air voids due to its weight, without any additional compaction. One of the main advantages of using SCC is the minimization of labor needed for finishing. The use of SCC decreases the costs and reduce the time of building. Segregation resistance of SCC is enhanced by modifying the mix proportions, e.g. reducing the $\mathrm{w} / \mathrm{c}$ ratio, increasing the fines content and add admixtures (Akers, et al., 2003; ACI (308-213), 2013 \& ASTM, C., 2013).

The term "curing" is used to describe the method to maintain moisture and temperature conditions of the mixture. The objectives of curing are to maintain the moisture of concrete and supply additional moisture and maintain the temperature of mixture for a sufficient period time (Pai, B. H. V., \& Sujith Kumar, C. P. 2009).

Many types of aggregate are used to produce concrete. They are commonly classified into three groups according to their weight, heavyweight aggregate (HWA), normal weight aggregate (NWA) and lightweight aggregate (LWA) (ASTM, C., 2000). Ferdinand Nebel from Koblenz who produced masonry blocks from pumice, with burnt lime the binder (ASTM, C., 2005), started the industrial use of natural LWA in 1845 in Germany. The LWA have low particle density because of the pore structure of molecules and higher porosity, higher porosity of LWA allow transportation of water and ions in the concrete mixture. LWA contains many small microscopic pores; this enables the aggregate to absorb between $15 \%-25 \%$ of its weight with water. This means LWA can supply the required water/moisture required for internal curing (Standard, A. S. T. M., 2012).

The water supplied from LWA called (Internal Curing Water) and the porous material (LWA) called (Internal Curing Material). The benefits of using internal curing in concrete were to reduce cracking, shrinkage and porosity and permeability. As well as it will help complete hydration of cement and decrease the density of concrete (ASTM, C., 2011). 
The distribution of water content in the mixture is the most important step in the internal curing process. The distance of the saturated LWA from the point in the cement paste, where the relative humidity (RH) drop takes place, determines the efficiency of the internal curing. If the water content is well distributed within the mixture, shorter distances have to be covered and the efficiency of the internal curing process is increased. These considerations lead to the choice of the small size of LWA rather than a large size of LWA for internal curing purposes (ASTM C 78-2, 2005).

The application of steel fibers in concrete is an important issue in concrete technology. Steel fibers proved to have the potential to increase the post-cracking energy absorption capacity of cement-based materials, enhancing the ductile character of concrete structures behavior, mainly of those with high redundant supports (B.S 1881:Part 116, 1989).

Plain concrete is a brittle material with low tensile strength and poor fracture toughness; it imposes numerous design constraints and often leads to longterm durability problems. Therefore, steel fiber can be added to concrete to improve toughness; increase resistance to impact; and improve abrasion resistance and flexural and shear strength "dlk069+6" (Bentz \& Snyder, 1999).

The objective of this study is to evaluate the effects of hooked end steel fiber on hardened properties of SCC with partially replaced of fine lightweight aggregate. Trail mixes were done to study the properties of SCC using locally sourced raw materials to correspond to international standards as presented in Table 1.

Table 1. Trail mixes were done to study the workability of SCC

\begin{tabular}{ccc}
\hline No. & Test & Range \\
\hline 1 & Slump flow & $650-800 \mathrm{~mm}$ \\
2 & T50 cm slump flow & $2-5 \mathrm{sec}$ \\
3 & $\mathrm{~J}$-Ring flow & $580-780 \mathrm{~mm}$ \\
4 & $\mathrm{~V}$-funnel & $6-12 \mathrm{sec}$ \\
5 & Increase in V-funnel at $\mathrm{T}_{5 \text { min }}$ & $+3 \mathrm{sec}, \mathrm{max}$ \\
6 & L-box $\left(\mathrm{H}_{2} / \mathrm{H}_{1}\right)^{*}$ & $0.8-1.0$ \\
\hline$* \mathrm{H}_{2} / \mathrm{H}_{1}$ the height of concrete at the end of the horizontal section to that remaining in the vertical section of & L-box. \\
\hline
\end{tabular}

\section{Method}

\subsection{Experimental Work/ Material and Concrete Mixture}

Locally sourced raw materials were provided to produce the SCC concrete mixes. Fine aggregate (Zone 2) and coarse aggregate, Limestone powder of $100 \mathrm{~kg} / \mathrm{m} 3$ with a surface area of $3150 \mathrm{~cm} 2 / \mathrm{gm}$ (Blain method) and silica fume of $50 \mathrm{~kg} / \mathrm{m} 3$ conform to ASTM, C., (2005), were implemented to increase the volume of mortar and then enhance workability. Cement content was $400 \mathrm{~kg} / \mathrm{m} 3$.

Porcelain stones were crushed into smaller size particles washed and cleaned with water to remove dust resulting from the crushing process and afterward dried by the oven. The crushed particles are sieved into different size fractions, and then every size of Porcelain aggregate is partially replaced by volume with the same size of sand with a $15 \%$ percentage to have the same grading as original aggregate $[\mathrm{x}, \mathrm{x}]$.

Table 2 shows the chemical and physical properties of porcelain aggregate. Before using the Porcelain aggregate in the mix, they were soaked in water for (24) hours that make the aggregate particles saturated.

Hooked ends steel fibers which are commercially known as Sika Fiber were also used throughout the experimental program. 
Table 2. Properties of Porcelain stones

\begin{tabular}{|c|c|c|c|}
\hline \multicolumn{2}{|c|}{ Physical Properties } & \multirow{2}{*}{$\begin{array}{c}\text { Chemical Compositions \% } \\
62.02\end{array}$} & \multirow{2}{*}{$\frac{\text { Oxide composition }}{\mathrm{SiO} 2}$} \\
\hline Crushed & Shape & & \\
\hline \multirow{3}{*}{1.35} & \multirow{3}{*}{ Apparent Specific Gravity } & 11.55 & $\mathrm{CaO}$ \\
\hline & & 7.2 & $\mathrm{MgO}$ \\
\hline & & 2.7 & $\mathrm{~A} 12 \mathrm{O} 3$ \\
\hline \multirow{2}{*}{855} & \multirow{2}{*}{ Bulk Density (Kg/m3) } & 0.87 & $\mathrm{Fe} 2 \mathrm{O} 3$ \\
\hline & & 0.18 & $\mathrm{TiO} 2$ \\
\hline \multirow{2}{*}{$30 \%$} & \multirow{2}{*}{ Absorption } & 0.3 & $\mathrm{SO} 3$ \\
\hline & & 13.86 & L.O.I \\
\hline
\end{tabular}

Table 3. Indicates the properties of steel fiber used*

\begin{tabular}{cc}
\hline Description & Hooked end \\
\hline Length & $30 \mathrm{~mm}$ \\
Diameter & $0.5 \mathrm{~mm}$ \\
Aspect ratio (L/D) & 60 \\
Relative Density & $7800 \mathrm{~kg} / \mathrm{m} 3$ \\
Ultimate Tensile Strength & $1180 \mathrm{MPa}$ \\
\hline
\end{tabular}

*According to manufacturer

\subsection{Mix Design}

Table 4. Mix proportion for fiber reinforced concrete SCC

\begin{tabular}{|c|c|c|c|c|c|c|}
\hline No. & Description of mixes & Mixes & $\begin{array}{l}\text { Aggregate } \\
\mathrm{kg} / \mathrm{m} 3\end{array}$ & $\begin{array}{l}\text { (LWA)Fine } \\
\mathrm{kg} / \mathrm{m} 3\end{array}$ & $\begin{array}{c}\text { dosage of } \\
\text { admixture } \\
L / m 3\end{array}$ & $\begin{array}{l}\text { Steel } \\
\text { Fiber } \\
\mathrm{kg} / \mathrm{m} 3\end{array}$ \\
\hline 1 & Ref. SCC Mix with Vf $=0 \%$ & $\begin{array}{c}\text { SCC } \\
0 \%\end{array}$ & 805 & 15 & 15 & 0 \\
\hline 2 & SCC Mix with $\mathrm{Vf}=0 \%$ and $15 \%$ LWA. & $\begin{array}{c}\text { IC-SCC } \\
0 \%\end{array}$ & 684 & 15 & 15 & 0 \\
\hline 3 & $\begin{array}{c}\text { SCC Mix with } \mathrm{Vf}=0.5 \% \text { and } 15 \% \\
\text { LWA }\end{array}$ & $\begin{array}{l}\text { IC-SF-SCC } \\
0.5 \%\end{array}$ & 684 & 16.5 & 16.5 & 42 \\
\hline 4 & SCC Mix with $\mathrm{V}_{\mathrm{f}}=1.0 \%$ and $15 \%$ LWA & $\begin{array}{c}\text { IC-SF-SCC } \\
1 \%\end{array}$ & 684 & 17.5 & 17.5 & 84 \\
\hline 5 & SCC Mix with $\mathrm{V}_{\mathrm{f}}=1.5 \%$ and $15 \%$ LWA & $\begin{array}{c}\text { IC-SF-SCC } \\
1.5 \%\end{array}$ & 684 & 19 & 19 & 126 \\
\hline
\end{tabular}

The mix constituents shall be identified so that segregation and bleeding are prevented while workability enhanced. A series of trial mixes were then carried out and the final five concrete mixes were obtained in compliance with standard acceptable (ASTM, C., 2000). The total powder content was $550 \mathrm{~kg} / \mathrm{m} 3$, which consist of cement $400 \mathrm{~kg} / \mathrm{m} 3$, silica fume $50 \mathrm{~kg} / \mathrm{m} 3$ and limestone $100 \mathrm{~kg} / \mathrm{m} 3$, the $W / C$ ratio of $0.4(160 \mathrm{~kg} / \mathrm{m} 3)$, and coarse aggregate content of $805 \mathrm{~kg} / \mathrm{m} 3$, the other materials are listed in Table 4. Resultant compressive strengths at 28 days were above $50 \mathrm{MPa}$ and workability values were above $650 \mathrm{~mm}$ and up to $790 \mathrm{~mm}$, for all mixes.

\subsection{Mixing of SCC}

The concrete was mixed using a drum mixer of $50 \mathrm{~L}$ capacity. In this study, the procedure of mixing follows the laboratory mixing procedure outlined by Emborg (Emborg, M., 2000), and modified by ASTM, C. (2000) as 
follows; at first, adding the fine aggregate to the mixer with $1 / 3$ water, and mixing for 1 minute, then adding the powder (cement+ limestone +silica fume) with another $1 / 3$ mixing water, and mixing for 1 minute, after that, the coarse aggregate is added with the last $1 / 3$ mixing water and $1 / 3$ of superplasticizer, and mixing for 1.5 minutes, at the end the remaining $2 / 3$ of the superplasticizer is added and mixed for 1.5 minutes, the mixture is then discharged and cast in molds. The total time of mixing was 5 minutes.

\subsection{Casting and Curing of SCC}

The steel molds $(100 \times 100 \times 100 \mathrm{~mm}$ cubes) for compression tests and cylinder with (dia. $=100, \mathrm{~h}=200 \mathrm{~mm})$ for splitting test, and $(100 \times 100 \times 400 \mathrm{~mm}$ prisms $)$ for the flexural test were well cleaned. The internal faces were thoroughly oiled to avoid adhesion with the concrete after hardening. SCC mixes do not require compacting, so the mixes were poured into the tight steel molds (cubes, cylinders, and prisms) until these molds were filled without any compaction. The molds were covered with a polyethylene sheets for about 24 hours to prevent loss of moisture from the surface and to avoid plastic shrinkage cracking. Then the specimens were be molded for curing. Specimens were kept after demolding in plastic bags sealed and saturated until the age of the test.

\subsection{Experimental Tests}

The experimental test program concludes to stages of the fresh and hardened test. The fresh test concludes the slump, J-Ring, L-box, and V funnel. These entire tests were down according to specifications and standards; the results of the hardened test were recorded;

1- Compressive Strength: conducted at 7,28 and 90 days of age for three cube specimens.

2- Splitting Tensile Strength: This test was conducted at ages 28, and 90 days of 3 specimens.

3- Modulus of Rupture: was carried out on $100 \times 100 \times 400 \mathrm{~mm}$ simply supported prisms. The specimens were tested at 28 , and 90 days and the rate of loading was about $0.015 \mathrm{MPa} / \mathrm{sec}$.

The average strength of three specimens was recorded, and it was indicated that fracture occurs within the central third for all specimens (Johnston, C. D. 2014; Degussa, 2002; Mehta, P. K., \& Monteiro, P. J., 2006).

\subsection{Absorption Test}

Absorption is the material property used to quantify the resistance to absorption. A lower value of the absorption means that water penetrated the concrete more slowly, and is indicative of higher quality concrete. This test method is used to determine the rate of absorption (absorption) of water according to ASTM, C. (2013) for both the concrete surface and internal concrete by measuring the increase in the mass of a specimen resulting from absorption of water as a function of time. The specimens were prepared by cutting a cylinder to three discs with a length of $50 \mathrm{~mm}$ and a diameter of $100 \mathrm{~mm}$ obtained from either molded cylinders by using an electrical saw. The samples are first placed in a $50{ }^{\circ} \mathrm{C}$ and $80 \% \mathrm{RH}$ environment. After three days of conditioning, the samples are removed from the oven and placed in individually sealed containers [Seal the side and top surface of each specimen with a suitable sealing material, where the samples are retained for 15 days to allow internal moisture equilibrium before the test begins. The mass of the sealed specimen is measured and recorded as the initial mass for water. The support device is placed at the bottom of the pan and the pan is filled with tap water so that the water level is 1 to $3 \mathrm{~mm}$ above the top of the support device.

\section{Results}

During the conductive of the trial mixes of this experiment, a reduction in workability were observed associated with adding steel fibers, subsequently, more water and/or higher dosage of high range water reducing agent were added to keep the slump, J-ring, L-box, and V-funnel test values. Table 4 as a workability measurement indicator, as much as possible within the acceptable standard limits. Accordingly, it suggests that from a practical point of view, steel fibers have definite adverse effects on the workability properties of fresh SCC. Consequently, higher chemical admixture dosages should be added. Table 5 shows the results of the fresh test.

Hardened test the results indicated in Table 6 described that all concrete specimens exhibited a continuous increase in strength with increasing curing age. 
Table 5. Test results for all fresh mixes

\begin{tabular}{|c|c|c|c|c|c|}
\hline \multirow{2}{*}{$\begin{array}{c}\text { Mix } \\
\text { Description }\end{array}$} & \multicolumn{2}{|c|}{ Slump flow } & \multirow{2}{*}{$\begin{array}{l}J \text {-Ring } \\
D(\mathrm{~mm})\end{array}$} & \multirow{2}{*}{$\begin{array}{c}L-B o x \\
H 1 / H 2\end{array}$} & \multirow{2}{*}{$\begin{array}{c}\text { V-Funnel } \\
\text { sec }\end{array}$} \\
\hline & $D(\mathrm{~mm})$ & T500(sec) & & & \\
\hline Ref SCC $0 \%$ & 775 & 3.5 & 755 & 0.96 & 6.2 \\
\hline IC-SCC 0\% & 768 & 4 & 737 & 0.92 & 6.7 \\
\hline IC-SF-SCC 0.5\% & 725 & 4.4 & 702 & 0.88 & 7.9 \\
\hline IC-SF-SCC 1\% & 689 & 4.8 & 669 & 0.85 & 9.8 \\
\hline IC-SF-SCC 1.5\% & 660 & 5 & 651 & 0.8 & 11.7 \\
\hline
\end{tabular}

Table 6. Test results for all specimens of SCC mixes

\begin{tabular}{ccccccccc}
\hline \multirow{2}{*}{$\begin{array}{c}\text { No. } \\
\end{array}$} & $\begin{array}{c}\text { Mixes } \\
\text { Description }\end{array}$ & \multicolumn{3}{c}{ Compressive strength $(\mathrm{MPa})$} & $\begin{array}{c}\text { Splitting tensile strength } \\
(\mathrm{MPa})\end{array}$ & $\begin{array}{c}\text { Modulus of Rupture } \\
(\mathrm{MPa})\end{array}$ \\
\cline { 3 - 9 } & & 7 days & 28 days & 90 days & 28 days & 90 days & 28 days & 90 days \\
\hline 1 & Ref SCC 0\% & 34.3 & 55 & 68.2 & 3.5 & 4.1 & 5.6 & 6.5 \\
2 & IC-SCC 0\% & 34.3 & 55.5 & 70.4 & 4 & 4.6 & 6.7 & 8 \\
3 & IC-SF-SCC 0.5\% & 35.8 & 58.3 & 74.3 & 5.1 & 5.8 & 9.5 & 10.1 \\
4 & IC-SF-SCC 1\% & 36.7 & 60.8 & 77.4 & 6.2 & 7.1 & 11.1 & 12 \\
5 & IC-SF-SCC 1.5\% & 38.2 & 62.1 & 80.2 & 7.3 & 8.2 & 12.7 & 13.6 \\
\hline
\end{tabular}

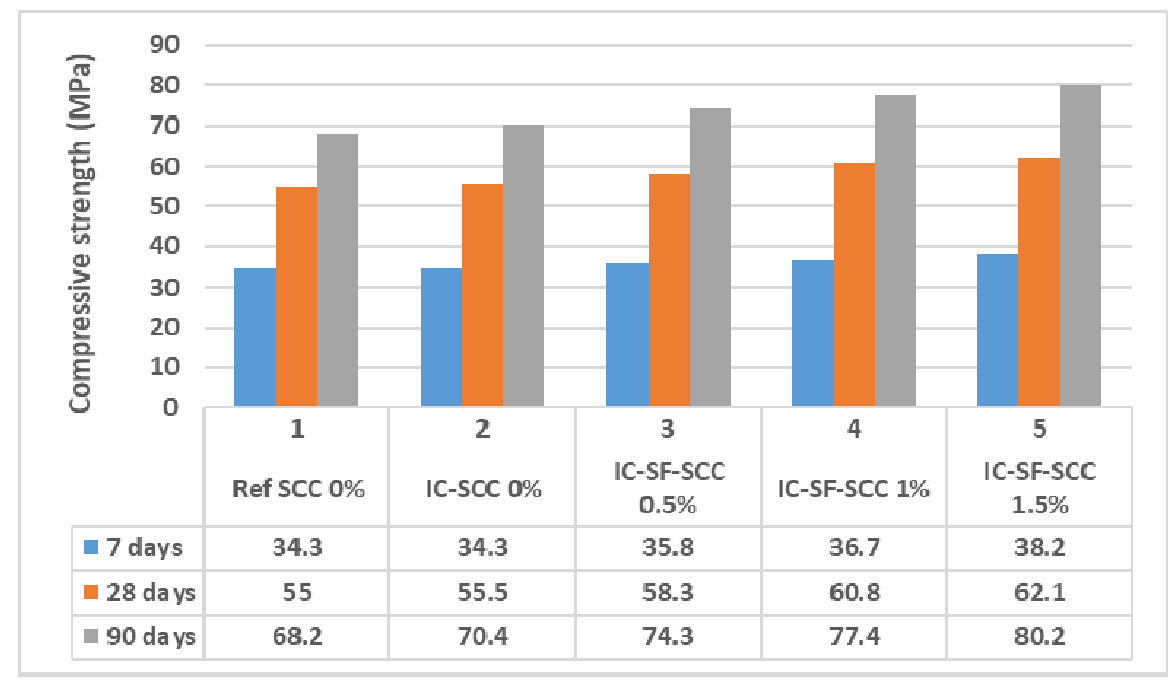

Figure 1. Test Compressive strength test results for all specimens of SCC mixes

The increase in compressive strength of the SCC containing steel fibers may be due to the increasing super-plasticizers dosage to retain and maintain their flowability and passing ability in the fresh state. The increase in compressive strength may be associated with a uniform dispersion of fine fibers throughout self-consolidating concrete of very high flowability, leading to consistent internal integrity. The results show clearly a slight increase in compressive strength for concretes incorporated superplasticizer (SF) for both ages 28 and 90 days.

Internally cured concretes shows similar compressive strengths performance, in comparison with Ref SCC concrete (Mix 1), the increases in the 28 days compressive strength of the Mixes $2,3,4$ and 5 were $(0.9 \%, 5 \%$, $10.5 \%$, and $12.9 \%)$ respectively and the increases after 90 days were $(3.2 \%, 8.9 \%, 13.5 \%$, and $17.6 \%)$ respectively. It may be attributed to the continuous hydration of the mixture at later ages that promoted by the 
extra water stored in the LWA particles.

Besides this was due to the improvement of the interfacial transition zone, enhanced hydration because of internal curing, and absence of shrinkage induced micro-cracking which can sustain the hydration process and filling the pores with hydration products and increase the compressive strength of concrete.

The increases in the 28 days splitting tensile strength of the Mixes 2, 3, 4 and 5 as a percent from reference Mix 1 were $(14.2 \%, 45.7 \%, 77.1 \%$, and $108.6 \%)$ respectively and the increases in the 90 days were $(12.2 \%$, $41.5 \%, 73.2 \%$, and $100 \%$ ) respectively as shown in Table 6 . The improvement caused by steel fiber and internal curing is much obvious for conducted splitting tensile tests than for compressive test results. The increment in strength at 90 days, for instance, reached for compressive strength about (3\%) for Mix 2, meanwhile, the splitting strength for the same mix reached to $(12.2 \%)$.

In comparison with mix 1 of SCC concrete, the increases in the 28 days modulus of rupture strength of the mixes $2,3,4$ and 5 were $(19.6 \%, 69.6 \%, 98.2 \%$, and $126.8 \%)$ respectively and the increases in the 90 days were $(23 \%$, $55.4 \%, 84.6 \%$, and $109.2 \%$ ) respectively as shown in Table 6 . The improvement caused by steel fiber is much obvious for modulus of rupture strength test than splitting tensile test and compressive test results. The Mix 5 (IC-SF-SCC 1.5\%) has the highest values of compressive, splitting and modulus of rupture strength value at 28 and 90 days among all mixes while the references mix (mix 1) SCC has the lowest strength value among all mixes at the same ages.

\subsection{Density}

An average of three tests for each mix the densities of the mixes were determined and listed in Table 7, the densities of the studied mixes are in the range of $(2560-2634)$. This increment refers to the low water/powder ratios and the employment of the superplasticizer, high powder content and the steel fibers in the mixes. The increases in the density of mixes 3,4 and 5 as a percent of mix 2 at 28 days were $(0.58 \%, 1.2 \%$, and $2 \%)$ respectively.

Table 7. Densities of the mixes

\begin{tabular}{ccc}
\hline \multicolumn{2}{c}{ Mixes Description } & Density $(\mathrm{kg} / \mathrm{m} 3)$ at 28 days \\
\hline Ref SCC & $0 \%$ & 2578 \\
IC-SCC & $0 \%$ & 2560 \\
IC-SF-SCC & $0.5 \%$ & 2575 \\
IC-SF-SCC & $1 \%$ & 2591 \\
IC-SF-SCC & $1.5 \%$ & 2611 \\
\hline
\end{tabular}

\subsection{Flexural Toughness and Load-Deflection Curves}

Prism specimens $100 * 100 * 400 \mathrm{~mm}$ were tested according to standard, A. S. T. M. (2012) standards for 28 , and 90 days of curing for flexural strengths and toughness. The load-deflection curves were presented in Figures $1 \&$ 2 and Toughness values were listed in Table 8 . It is characterized by the post-peak portion of the area under the load-deflection curve obtained during a flexural test on $100 * 100 * 400 \mathrm{~mm}$ beams in a four-point loading arrangement for deflection of L/150.

Linear-elastic material behavior characterizes SCC, so the specimens fail explosively without any warning as in Figure 1 for mixes without steel fiber in which the failure is clear to be brittle. For specimens incorporating steel fibers, the load-deflection behavior and consequently the ductility and fracture toughness can be improved. This can be traced back to the fact that the fibers can transfer emerging loads by bridging the cracks. Here increasing the fiber content from 0 to $42 \mathrm{~kg} / \mathrm{m} 3$ to $84 \mathrm{~kg} / \mathrm{m} 3$ and finally, $128 \mathrm{~kg} / \mathrm{m} 3$ make an impact after the appearance of cracks.

The property of flexural toughness relates to the ability of the concrete to absorb energy, after micro-crack formation, while the fibers hold the matrix together. 


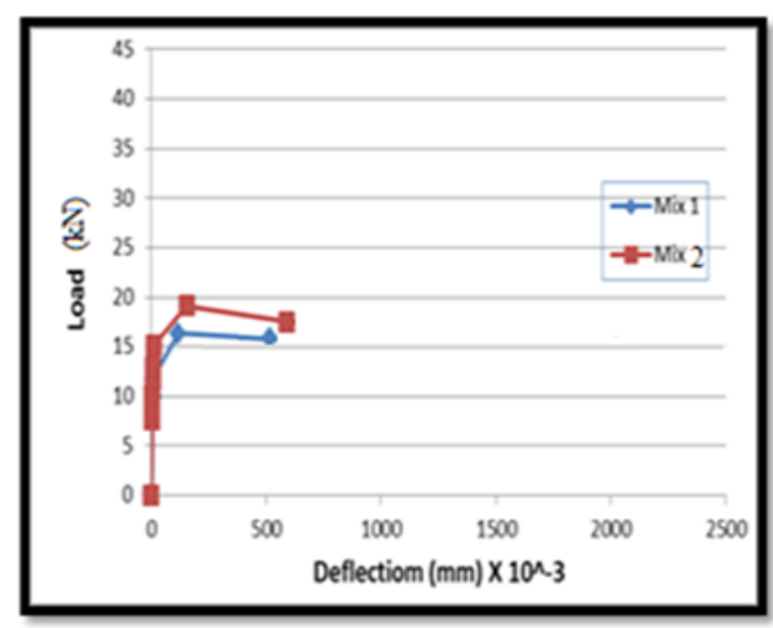

a) 28 days

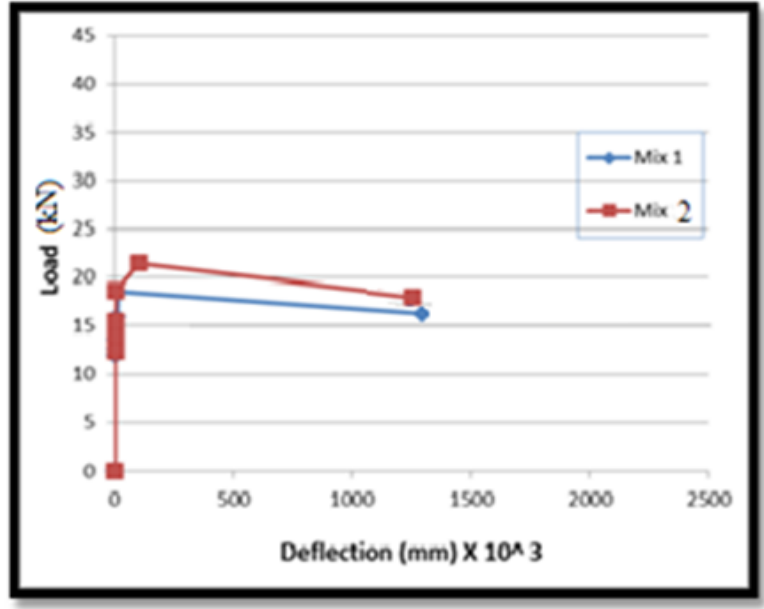

b) 90 days

Figure 2. Flexural load- deflection curves for mixes $1 \& 2$ at $28 \& 90$ days

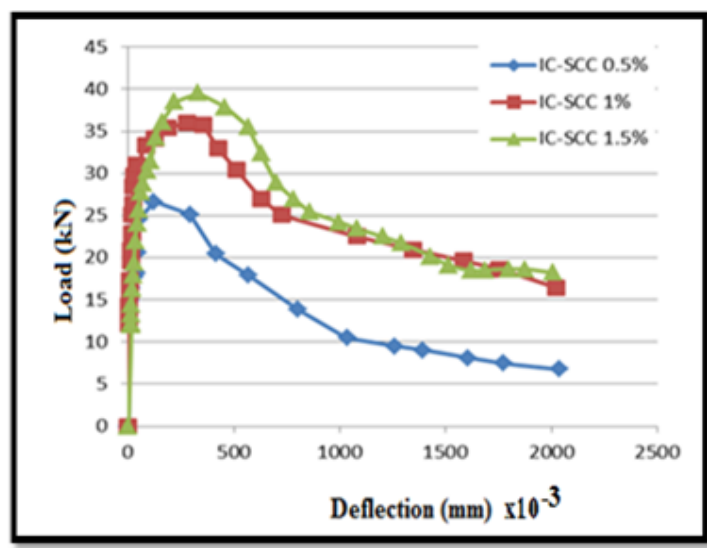

a) 28 days

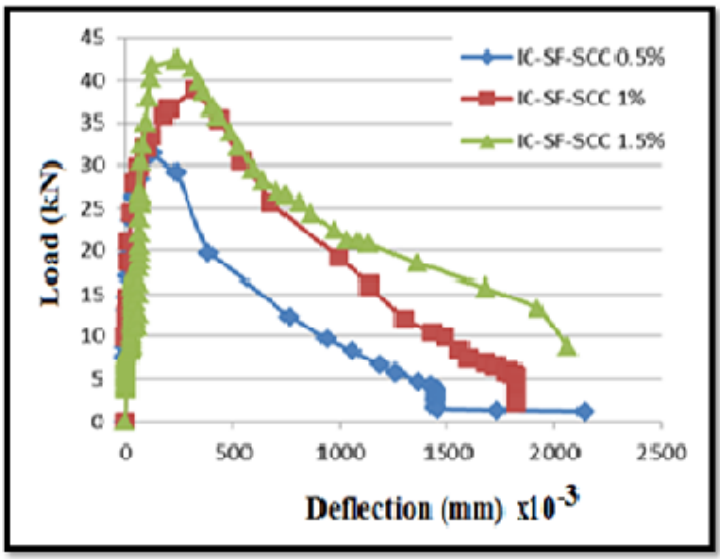

b) 90 days

Figure 3. Flexural load- deflection curves for mixes3, $4 \& 5$ at $28 \& 90$ days

Flexural toughness can be defined as the area under the load-deflection curve in flexure up to deflection of $(\mathrm{L} / 150) \mathrm{mm}$, which is the total energy absorbed before complete separation of the specimen. This was done to allow for removal of the instability part from the load-deflection curve to calculate the toughness values.

A $\mathrm{s}$ indicated in Table 8, the increase in the toughness value for mixes with internal curing by fine LWA curing was noticed after 28 days and 90 days curing. Mix 5 (IC-SF-SCC 1.5\%) has the highest toughness value at 28 and 90 days among the mixes while and the reference Mix (mix 3) (SF-SCC 0.5\%) has the lowest toughness value at the same age.

Table 8. Toughness values of SCC mix with LWA and steel fiber

\begin{tabular}{cccc}
\hline $\begin{array}{c}\text { Mix } \\
\text { No. }\end{array}$ & Mixes description & Toughness after 28 days & Toughness after 90 days \\
\hline 3 & IC-SF-SCC 0.5\% & 38.9 & 48.4 \\
4 & IC - SF-SCC 1 \% & 47.7 & 56.7 \\
5 & IC-SF-SCC 1.5\% & 55.2 & 63.6 \\
\hline
\end{tabular}




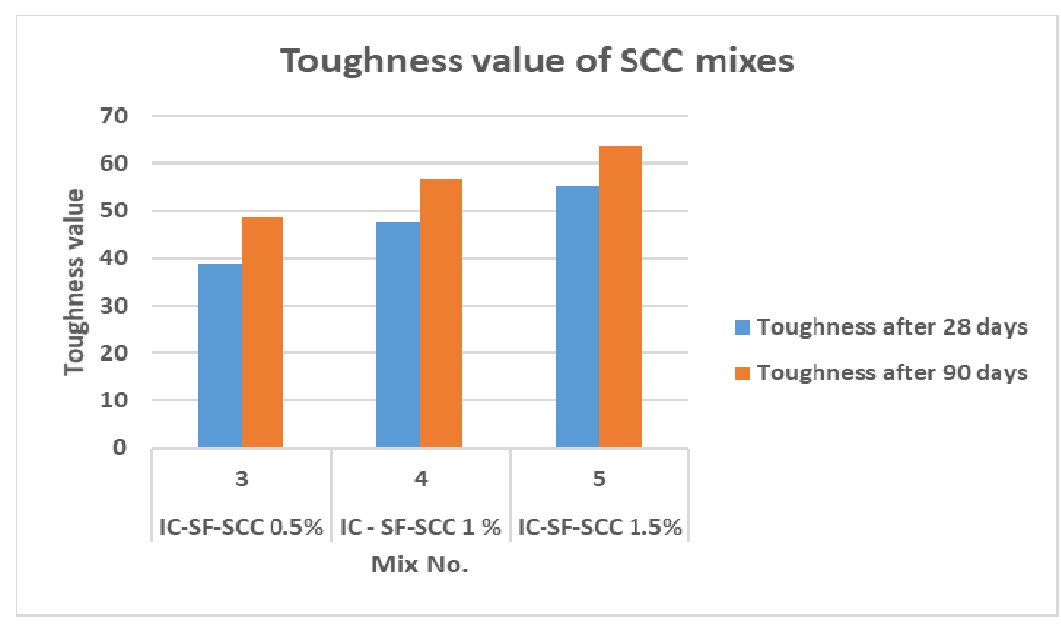

Figure 4. Toughness values chart of SCC mixes with LWA and steel fiber

\subsection{Absorption Test}

Tables 9, 10 and 11 show the values of absorption for 3 SCC mixes. The results indicated that all concrete specimens exhibited a continuous reduction in absorption values with the time of curing. The total absorption for all SCC specimens exposed to water was below $10 \%$ by weight. This gives an indication of good concrete (with low permeability) and it may be attributed to the continuous hydration of cement which decreases the absorption of SCC, as well as, due to the dense microstructure of SCC with low W/C ratio used and the presence of silica fume. This causes modification to the microstructure of concrete, reduces the capillary pores leading to better packing, increase the density and lead to a reduction in the absorption percentage (Teknik, D. B., 2005; Nehdi, M., \& Ladanchuk, J. D., 2004)

The absorption test was carried on 3 mixes 1, 2 and 5 to conclude the effect of steel fibers and internal curing by fine LWA on the absorption results. Besides the decrease in the absorption of the Mix 5 may be due to the increase in super-plasticizers' dosage to retain and maintain their flowability and passing ability of this mix in the fresh state.

Table 9. Absorption test for Ref mix 1 (SCC 0\%)

\begin{tabular}{cccccc}
\hline Time $(\mathrm{hrs})$. & Time $(\mathrm{sec})$ & $\sqrt{\text { Time }}(\mathrm{sec})$ & Mass $(\mathrm{gm})$ & A Mass $(\mathrm{gm})$ & $I(\mathrm{~mm})$ \\
\hline 0 & 0 & 0 & 990 & 0 & 0 \\
$10(\mathrm{~min})$ & 600 & 24 & 999 & 9 & 1.1464 \\
1 & 3600 & 60 & 1002.4 & 12.4 & 1.5796 \\
2 & 7200 & 85 & 1004 & 14 & 1.7834 \\
24 & 92220 & 304 & 1009.8 & 19.8 & 2.5222 \\
72 & 268500 & 518 & 1012.6 & 22.6 & 2.8789 \\
120 & 432000 & 657 & 1013.7 & 23.7 & 3.0191 \\
192 & 691200 & 831 & 1014.3 & 24.3 & 3.0955 \\
\hline
\end{tabular}


Table 10. Absorption test for Mix 2 (IC-SCC 0\%)

\begin{tabular}{cccccc}
\hline Time (hrs.) & Time $(\mathrm{sec})$ & $\sqrt{\text { Time }}(\mathrm{sec})$ & Mass $(\mathrm{gm})$ & D Mass $(\mathrm{gm})$ & I $(\mathrm{mm})$ \\
\hline 0 & 0 & 0 & 852.3 & 0 & 0 \\
$10(\mathrm{~min})$ & 600 & 24 & 858.1 & 5.8 & 0.7388 \\
1 & 3600 & 60 & 865.7 & 13.4 & 1.707 \\
2 & 7200 & 85 & 866.4 & 14.1 & 1.7961 \\
24 & 86400 & 304 & 873 & 20.7 & 2.6369 \\
72 & 259200 & 518 & 876.4 & 24.1 & 3.07 \\
120 & 432000 & 657 & 877.5 & 25.2 & 3.2101 \\
192 & 691200 & 831 & 878.8 & 26.5 & 3.37579 \\
\hline
\end{tabular}

Table 11. Absorption test for Mix 5 (IC-SF-SCC 1.5\%)

\begin{tabular}{cccccc}
\hline Time $(\mathrm{hrs})$. & Time $(\mathrm{sec})$ & $\sqrt{\text { Time }}(\mathrm{sec})$ & Mass $(\mathrm{gm})$ & U Mass $(\mathrm{gm})$ & I (mm) \\
\hline 0 & 0 & 0 & 942.4 & 0 & 0 \\
$10(\mathrm{~min})$ & 600 & 24 & 947.2 & 4.8 & 0.6114 \\
1 & 3600 & 60 & 952.7 & 10.3 & 1.3121 \\
2 & 7200 & 85 & 953.1 & 10.7 & 1.3630 \\
24 & 86400 & 304 & 961.3 & 18.9 & 2.4076 \\
72 & 259200 & 518 & 963.2. & 20.8 & 2.6496 \\
120 & 432000 & 657 & 964.3 & 21.9 & 2.7898 \\
192 & 691200 & 831 & 965.3 & 23 & 2.9299 \\
\hline
\end{tabular}

\section{Discussion}

Kundgol, M. N. F., \& Vijapur, V. (2016) investigated the use of superabsorbent polymer to achieve the internal curing property. The compressive, split tensile, flexural, shear, and impact strength was found to discuss the effect of the superabsorbent polymer, the results were found $0.1 \%$ to $0.4 \%$ by weight of cement as a range of the superabsorbent polymer, and the steel fiber percentage was $2 \%$ by volume of concrete. The authors indicated that the steel fiber strengthens the concrete compressive strength and the other mechanical prosperities.

According to Zhang et. al. the orthogonal experiment was used to create a practical reactive powder concrete mixture ratio, the researchers used steel fiber as a reinforcing agent. The tests were used; compressive and splitting tensile strength tests, the paper discusses the analysis of these tests by comparing the natural, standard, and compound curing and investigated the improvement effect of steel fiber content to enhance the compressive performance and tensile strength. The authors found that under the three curing conditions, the optimal steel fiber content was $4 \%$. The standard curing was found stronger than natural curing and the compound was stronger than both other curing types (Zhang, Y., et al., 2019).

In Alyousef et. al. research the using of steel fiber reinforcement-self compacting concrete was developed and the researcher investigated the effectiveness of mechanical properties of the SFR-SCC mixture by different cement replacement materials. The paper results simulated the hardened behavior of the concrete specimens by determining the compressive strength and splitting tensile strength tests. The results of experiments in the research were $10 \%$ silica fume which increased the tensile and flexural strength, the steel fiber percentage was $2 \%$ of total weight. The use of steel fibers was found to strengthen the compressive and splitting tensile in the self-compacting concrete mixes (Alabduljabbar, et al., 2019)

The results show clearly that the important increment all strength for concretes with SF and internal curing was at 28 and 90 days more than that of SCC with SF only. These results may be associated with the continuous hydration of the mixture at later ages promoted by the extra water stored in the LWA and could be the cause of that increase. Also, this was due to the improvement of the interfacial transition zone, enhanced hydration because of internal curing, and absence of shrinkage-induced micro-cracking, which can sustain the hydration 
process and filling the pores with hydration products and increase the modulus of rupture of concrete. The improvement caused by internal curing is much obvious for conducted for modulus of rupture than splitting tensile and compressive test results. The results go with the result of Jayeshkumar and Umrigar (Pitroda, J., et al., 2013), but in this paper, the test method was developed to get accurate results that show the specific effect of using fiber steel and internally curing.

The increment in the super-plasticizers' dosage will lead also to a more uniform microstructure and because of that, the water sorption decreases and hence the durability performance of the mixes is improved. The increase in the absorption values of mix 2 may relate to the presence of pre-wetted fine LWA that has more pores than ordinary fine aggregate, which leads to more absorption.

\section{Conclusions}

Based on the experimental work results in this investigation, the following conclusions can be drawn:

1. All SCC mixes that incorporated hooked end steel fiber has slightly higher compressive strength at all curing ages and for both curing types used where the increase in compressive strength.

2. The fine aggregate replacement as internal curing material caused a better enhancement in mechanical properties (strengths) of SCC than coarse aggregate replacement. Meanwhile, the replacement for coarse aggregate caused decreasing in compressive strength at the same percentage.

3. The improvements in SCC's strengths caused by using fine LWA for internal curing and steel fibers were more than that caused by steel fibers only.

4. The toughness of SCC was increased with the increase of steel fibers content and also with the application of internal curing for both 28 and 90 days ages.

5. There was an increase in the density of SF-SCC due to the presence of steel fibers, and there was a decrease in the density of internally cured SCC mixes due to the use of fine LWA for internal curing.

6. Regardless of the curing methods used the absorption of SCC decreases with the increase in steel fibers content for instance when the absorption of SCC $0 \%$ reached $3.09 \mathrm{~mm}$ after 8 days, the absorption of SF-SCC $1.5 \%$ reached to $2.77 \mathrm{~mm}$ during the same time.

\section{References}

ACI (308-213) R-13. (2013). Report on Internally Cured Concrete Using Prewetted Absorptive Lightweight Aggregate. American Concrete Institute Committee 308, Farmington Hills, MI. ISBN: 9780870318214

Akers, D. J., Gruber, R. D., Ramme, B. W., Boyle, M. J., Grygar, J. G., Rowe, S. K. \& Kowalsky, M. J. (2003). Guide for Structural Lightweight-Aggregate Concrete. American Concrete Insttitute. ACI 213R-03 http://dl.sazepardaz.com/Documents/ACI\%20Code/ACI\%20213R-03\%20Guide\%20for\%20Structural\%20 Lightweight-Aggregate\%20Concrete.pdf

Alabduljabbar, H., Alyousef, R., Alrshoudi, F., Alaskar, A., Fathi, A. \& Mustafa Mohamed, A. (2019). Mechanical Effect of Steel Fiber on the Cement Replacement Materials of Self-Compacting Concrete. Fibers, 7(4), 36. https://doi.org/10.3390/fib7040036

ASTM C 78-02. (2005). Standard Test Method for Flexural Strength of Concrete. American Society for Testing and Materials. https://doi.org/10.1520/C0078-02

ASTM, C. (2000). 192/C 192M: The American Society for Testing Materials Standard Practice for Making and Curing Concrete Test Specimens in the Laboratory. West Conshohocken (PA), USA. https://doi.org/10.1520/C0192_C0192M-16A

ASTM, C. (2005). 1240-15 Standard, Specification for silica fume used in cementitious mixtures. West Conshohocken, PA, American Society for Testing and Materials. https://doi.org/10.1520/C1240-15

ASTM, C. (2011). Standard test method for splitting tensile strength of cylindrical concrete specimens. C496/C496M-11. https://doi.org/10.1520/C0496_C0496M-11

ASTM, C. (2013). 1585-13 Standard test method for measurement of rate of absorption of water by hydraulic cement concrete. West Conshohocken, PA. https://doi.org/10.1520/C1585-13 http://www.astm.org/cgi-bin/resolver.cgi?C1585-13

B.S 1881 : Part 116 (1989). Method for determination of compressive strength of concrete cubes. British Standards Institution. London BS. ISBN 0580129500

Bentz, D. P. \& Snyder, K. A. (1999). Protected paste volume in concrete: Extension to internal curing using 
saturated lightweight fine aggregate. Cement and concrete research, 29(11), 1863-1867. https://doi.org/10.1016/S0008-8846(99)00178-7

Degussa. (2002). Construction Chemicals. Glenium 51 Technical Date Sheet, 06 /97 MBT-ME.

Emborg, M. (2000). Mixing and transport. Final report of task, 8.1, Betongindustri AB, BriteEuRam, Sweden, 65 pp. Brite EuRam Proposal No. BE96-3801 Brite EuRam Contract No. BRPR-CT96-0366

Johnston, C. D. (2014). Fiber-reinforced cements and concretes. Crc Press. https://doi.org/10.1201/9781482298154

Kundgol, M. N. F. \& Vijapur, V. (2016). Study on Internal Curing of Steel Fiber Reinforced Concrete Using Super Absorbent Polymer. International Research Journal of Engineering and Technology, 3, p-ISSN: 2395-0072.

Mehta, P.K. \& Monteiro, P.J.M. (2006) Concrete: Microstructure, Properties, and Materials. 3rd Edition. McGraw-Hill, New York. http://dx.doi.org/10.1036/0071462899

Nehdi, M. \& Ladanchuk, J. D. (2004). Fiber synergy in fiber-reinforced self-consolidating concrete. Materials Journal, 101(6), 508-517. http://dx.doi.org/10.1590/s1983-41952019000200005

Okamura, H. (1997). Self-compacting high-performance concrete. Concrete International, 19(7), 50-54. https://doi.org/10.1002/pse.2260010406

Pai, B. H. V. \& Sujith Kumar, C. P. (2009, August). Experimental study on steel fiber reinforced self compacting concrete with silica fume as filler material. In published in 34th Conference on OUR WORLD IN CONCRETE \& STRUCTURES (pp. 16-18). https://doi.org/10.13140/RG.2.2.19955.89127

Pitroda, J., Umrigar, F. S., Principal, B. \& Anand, G. I. (2013). Evaluation of sorptivity and water absorption of concrete with partial replacement of cement by thermal industry waste (Fly Ash). International Journal of Engineering and Innovative Technology (IJEIT), 2(7), 245-249. ISSN: 2277-3754

Standard, A. S. T. M. (2012). Standard test method for flexural performance of fiber-reinforced concrete (using beam with third-point loading). ASTM - C1609. https://doi.org/10.1520/C1609_C1609M-19

Teknik, D. B. (2005). Measurement of Properties of Fresh Self-Compacting Concrete. Final Report, 15, 55-57. European Union Growth Contract No. G6RD-CT-2001-00580

Zhang, Y., Wu, B., Wang, J., Liu, M. \& Zhang, X. (2019). Reactive Powder Concrete Mix Ratio and Steel Fiber Content Optimization under Different Curing Conditions. Materials, 12(21), 3615. https://doi.org/10.3390/ma12213615

\section{Copyrights}

Copyright for this article is retained by the author(s), with first publication rights granted to the journal.

This is an open-access article distributed under the terms and conditions of the Creative Commons Attribution license (http://creativecommons.org/licenses/by/3.0/). 